\title{
Study on Microclimate Characteristics and Vertical Variation of Potential Evapotranspiration of the Robinia pseudoacacia Forest in the Loess Plateau of China
}

\author{
Jianjun Zhang, Baoni Guo, Qun'ou Jiang, Hao Ru, and Zhen Wang \\ School of Soil and Water Conservation, Beijing Forestry University, Beijing 100038, China \\ Correspondence should be addressed to Qun’u Jiang; jiangqo.dls@163.com
}

Received 20 May 2013; Revised 20 July 2013; Accepted 30 July 2013

Academic Editor: Xiangzheng Deng

Copyright (c) 2013 Jianjun Zhang et al. This is an open access article distributed under the Creative Commons Attribution License, which permits unrestricted use, distribution, and reproduction in any medium, provided the original work is properly cited.

With the water and soil conservation forests of Robinia pseudoacacia in the Malian beach of Hongqi farm, Ji County, Shanxi province, as the research object, this study estimated the potential evapotranspiration in the open space outside the forest and at the heights of $3 \mathrm{~m}, 6 \mathrm{~m}$, and $10 \mathrm{~m}$ in the forests with the climate data during 2011-2012 and the upgraded Penman-Monteith formula; then, this study explored the microclimate characteristics inside and outside the Robinia pseudoacacia forest and thereafter revealed the vertical variation rules of potential evapotranspiration of Robinia pseudoacacia. The results indicate that the air temperature, relative humidity, wind speed, and potential evapotranspiration at different heights above the ground surface showed similar changing trends, but with some variation during different periods. In addition, the weather also had impacts on the potential evapotranspiration. In April, July, and October, the change of potential evapotranspiration of the Robinia pseudoacacia forests showed a bimodal curve in the sunny days and rainy days, while it showed a single-peak curve with quite small fluctuation in the rainy days. However, it showed a single-peak pattern even in the sunny days in January, and it showed no fluctuation in the snowy days in January.

\section{Introduction}

Global warming and the shortage of fresh water resources have become the most serious ecological and environmental problems faced by the sustainable development of human society in the 21st century. Evapotranspiration process is the significant feedback factor in global warming and attracts the particular concern of the scientific community of ecology and global changes. Potential evapotranspiration is the theoretical upper limit of real evapotranspiration and is also the basis of estimating the evapotranspiration [1-4]. Recognizing its temporal dynamics and control factors is the process of evaluation and prediction of evapotranspiration role in the climate system basis [5]. Forest water consumption is the most important element of the water balance of the forest hydrology and the dependence for choosing the soil and water conservation forest and forest management. It is the foundation to create a parody of natural forests and improve the low quality inefficiency $[6,7]$. Therefore, forest water consumption is one of the hot issues in the field of forest hydrology, ecology, and silviculture.

In the semiarid Loess Plateau, there is rare vegetation and serious soil erosion, and water plays a key role in the growth of vegetation. Therefore, water surplus and deficit in the forest correspondingly become one of the concerning issues in this region [8]. Plant transpiration constitutes the main part of the plant's water consumption in the semiarid and arid areas of Loess Plateau, thus potential evapotranspiration becomes the main focus in the Loess Plateau. Researches on the variation of potential evapotranspiration are not only the key link of water circulation of soil-vegetation-atmosphere system, but also determine the regional ecological water demand [9]. Robinia pseudoacacia is one of the main tree species in the soil and water conservation planning of Loess Plateau, analysis of potential evapotranspiration changing trends of Robinia pseudoacacia will be beneficial to explore the relationship 
between the plant's water consumption and climate change and will provide the scientific basis for water circulation of soil-vegetation-atmosphere system.

There are amounts of methodologies for calculating water consumption on potential evapotranspiration, including the Penman-Monteith formula, Hargreaves formula, and Ivanov formula recommended by FAO, for example, among which the Penman-Monteith formula application is the most popular [10-12]. In recent years, many scholars have applied the Penman-Monteith formula to evaluate the potential evapotranspiration of forestry area; moreover, there are also plenty of scholars who updated the Penman-Monteith formula which is more suitable for the climatic characteristics in China [13-15]. Robinia pseudoacacia is one of the principal species for soil and water conservation in western Loess Plateau, reasonable Robinia pseudoacacia artificial forest for soil and water conservation is therefore extremely significant for the rational utilization of water resource. There have been some researches on the water consumption rules of soil and water conservation forest $[16,17]$. Zhou et al. conducted an investigation on the evapotranspiration characteristics of different densities of Robinia pseudoacacia during the peak potential evapotranspiration period and obtained a reasonable density of a 15-year-old Robinia pseudoacacia in loess area [18]. Liu et al. studied the potential evapotranspiration of mixed Pinus tabulaeformis and Robinia pseudoacacia forest with different diameters [19]. However, rare research is conducted on the vertical potential evapotranspiration variation of Robinia pseudoacacia forest with season and time changes. Vertical potential evapotranspiration has some effects on the microclimate change such as relative humidity and air temperature to some extent [20]. So, it is significant to study the vertical potential evapotranspiration.

Based on the meteorological data derived from meteorological station in Robinia pseudoacacia forest and open space outside the forest, this study applies the upgraded PenmanMonteith formula, which has been proved to be suitable for the Shanxi province [21], to estimate the potential evapotranspiration of Robinia pseudoacacia at the different heights in the forest and the open space outside the forest, explore the different microclimate characteristics between the inside and outside of Robinia pseudoacacia forest, and analyze the potential evapotranspiration dynamics of Robinia pseudoacacia with time and season changes. All the conclusions are expected to provide the references for the rational water resource utilization during the process of Robinia pseudoacacia afforestation in the loess area of western Shanxi province.

\section{Study Area}

The study area is located in the Malian Beach of Hongqi Forest Farm, Ji County, Shanxi province, between E110 $45^{\prime} 04^{\prime \prime}$ to $\mathrm{E} 110^{\circ} 47^{\prime} 38^{\prime \prime}$ and $\mathrm{N} 36^{\circ} 00^{\prime} 15^{\prime \prime}$ to $\mathrm{N} 36^{\circ} 04^{\prime} 32^{\prime \prime}$ (Figure 1). It belongs to the gully region of the Loess Plateau in western Shanxi province, with an average altitude of 965 to $1,345 \mathrm{~m}$. Its annual average temperature is $10^{\circ} \mathrm{C}$, and the average annual precipitation is $575.9 \mathrm{~mm}$, while its annual average water surface evaporation reaches $1,732.9 \mathrm{~mm}$. It has a relatively dry climate, concentrated rainfall, sparse vegetation, serious soil

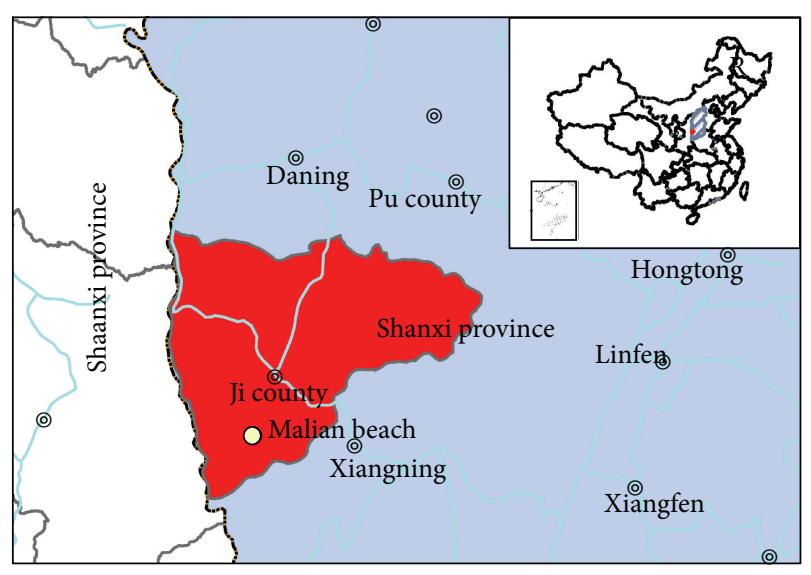

FIgURE 1: Location of the sample plot.

erosion, and loess-derived cinnamon soil. Comprehensive management on Loess Plateau is a key project of natural reform engineering in China, and its principles are soil and water conservation. In the study area, the forest coverage rate is $45 \%$, and the main soil and water conservation forest species are Pinus tabulaeformis and Robinia pseudoacacia, and the major shrub species are Hippophae rhamnoides and Ostryopsis davidiana [21].

\section{Methodology}

This study takes the soil and water conservation forest of Robinia pseudoacacia in the Malian beach as the sample plot and investigates the parameters of Robinia pseudoacacia in the study area, that is, tree height, diameter at breast height (DBH), and thickness of the litter. The details are shown in Table 1.

Meteorological data are all derived from the two meteorological stations in the study area. One is installed in the forest of Robinia pseudoacacia, which can record the relative humidity, air temperature, solar radiation, wind speed, sunshine hours, and other meteorological factors data every 30 minutes at the heights of $3 \mathrm{~m}, 6 \mathrm{~m}$, and $10 \mathrm{~m}$ above the ground surface inside the forest. Another one is installed in the open space outside the forest of Robinia pseudoacacia, which is also used to measure the same meteorological factors every 30 minutes.

Based on the observed meteorological data, this study applies the updated Penman-Monteith formula to estimate the potential evapotranspiration of Robinia pseudoacacia forest at different heights and of the open space. Penman-Monteith formula is one of the most popular formulas for potential evapotranspiration evaluation; though its principle is applicable in different regions, some of its empirical coefficients are subjected to regional conditions. Kang corrected the empirical coefficient to make it more suitable for the potential evapotranspiration estimation in Shanxi province as follows [21]:

$$
E_{0}=\left(2.37 e^{0.047 T}+6.28 \frac{n}{N}-3.42\right)(0.29 V+0.47) .
$$


TABLE 1: Basic situation of the sample plot.

\begin{tabular}{lcccccccc}
\hline $\begin{array}{l}\text { Vegetation } \\
\text { type }\end{array}$ & $\begin{array}{c}\text { Sample area } \\
\left(\mathrm{m}^{2}\right)\end{array}$ & $\begin{array}{c}\text { Slope } \\
\left({ }^{\circ}\right)\end{array}$ & Aspect & $\begin{array}{c}\text { Elevation } \\
(\mathrm{m})\end{array}$ & $\begin{array}{c}\text { Stand age } \\
(\text { years })\end{array}$ & $\begin{array}{c}\text { Canopy } \\
\text { density } \\
(\%)\end{array}$ & $\begin{array}{c}\text { Mean tree } \\
\text { height }(\mathrm{m})\end{array}$ & $\begin{array}{c}\text { Mean } \\
\mathrm{DBH}(\mathrm{cm})\end{array} \begin{array}{c}\text { Planting } \\
\text { space } \\
(\mathrm{m} \times \mathrm{m})\end{array}$ \\
\hline $\begin{array}{l}\text { Robinia } \\
\text { pseudoacacia }\end{array}$ & 200 & 6 & $\mathrm{~N} 133$ & 1243 & 17 & 60 & 11.4 & 11.1 \\
\hline
\end{tabular}

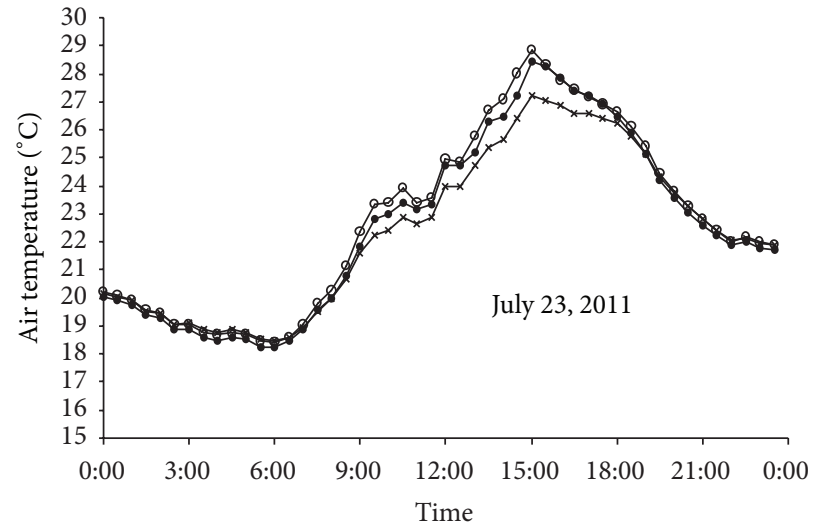

(a)

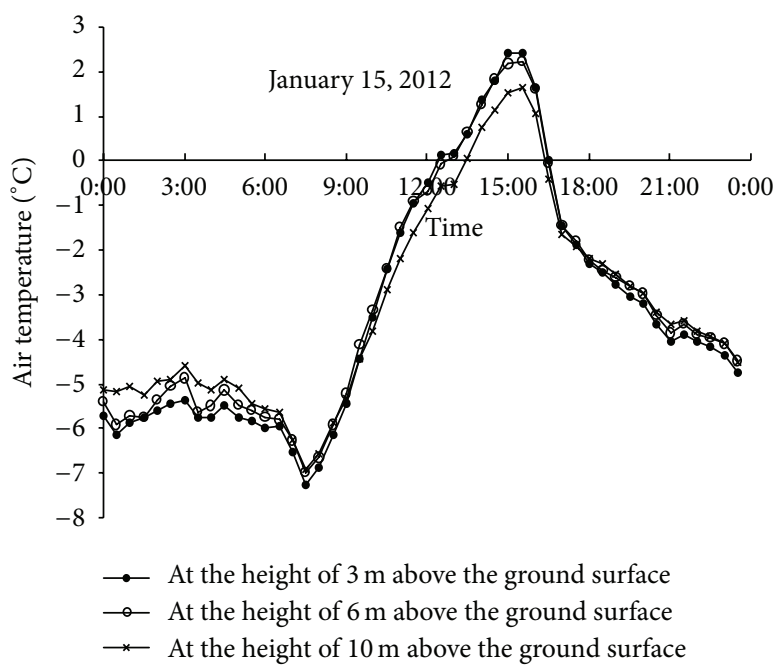

(c)

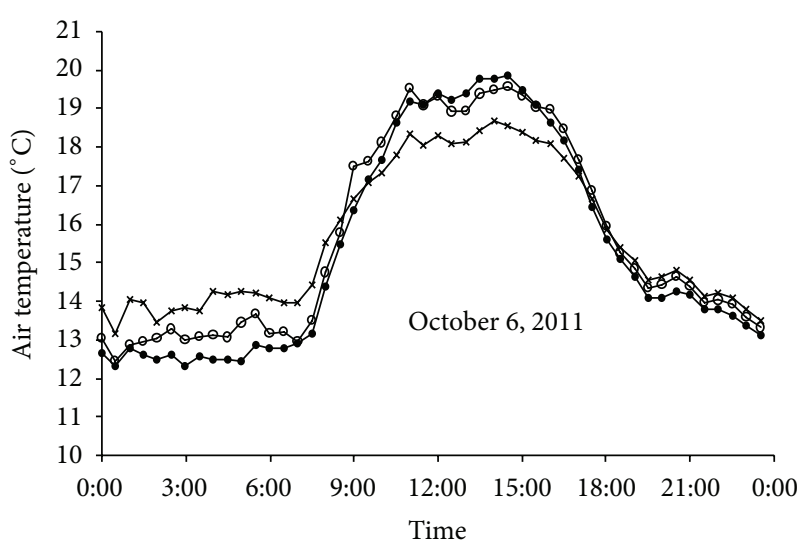

(b)

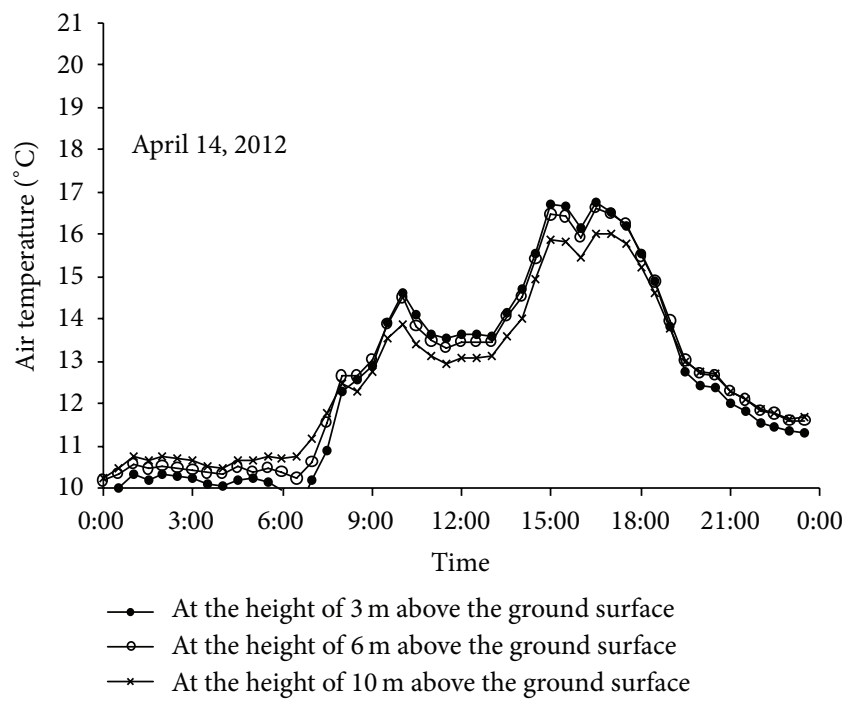

(d)

FIgURE 2: Dynamic variation of air temperature at the heights of $3 \mathrm{~m}, 6 \mathrm{~m}$, and $10 \mathrm{~m}$ above the ground surface inside the forest.

The reliability of the new semiempirical formula was validated through comparative analysis by Kang. The new semiempirical formula with higher precision is based on Dalton Moisture Diffusion Law, including three meteorological factors, that is, air temperature $T\left({ }^{\circ} \mathrm{C}\right)$, sunshine ratio $n / N$, and wind speed $V(\mathrm{~m} / \mathrm{s})$.

\section{Microclimatic Characteristics inside the Robinia pseudoacacia Forest}

4.1. Vertical Variation of Air Temperature inside the Forest. This study selected four typical sunny days, that is, July 23 and October 6 in 2011; January 15 and April 14 in 2012, recorded the air temperature at the heights of $3 \mathrm{~m}, 6 \mathrm{~m}$, and $10 \mathrm{~m}$ above the ground surface inside the Robinia pseudoacacia forest, and analyzed the daily dynamic changes, respectively. The results indicated that the air temperature inside the Robinia pseudoacacia forest had the similar variation at different heights; however, the changing extents at different times were various. Moreover, the air temperature inside the Robinia pseudoacacia forest showed significant circadian variation.

On July 23, 2011, the air temperature at different heights inside the Robinia pseudoacacia forest all started rising rapidly from around 6:00, went up to the peak at about 15:00, and then dropped down (Figure 2). The air temperature differences between different heights were all near zero during 
18:00-23:00 and 0:00-9:00. Maybe because the solar radiation of this period was close to zero, the absorbed heat from different heights of the forest was relatively small, and the radiated heat was almost the same; therefore, the air temperature was basically consistent. In addition, it should be noted that there was a partial temperature inversion phenomenon, which means that the air temperature at the height of $6 \mathrm{~m}$ was higher than that at the height of $3 \mathrm{~m}$ from 9:00 to 15:00.

While on October 6, 2011, the air temperature changing trend, which had a broad curve, differed from that in July. It began to increase from 7:00, reached the peak at around 11:00, and then declined after it sustained at the peak for about four hours (Figure 2). There was the temperature inversion phenomenon as well, but it occurred from 18:00 to 23:00 and 0:00 to 9:00, and the air temperature grew from the ground surface to the forest canopy. Perhaps this was because the air temperature in the night of October was low, and the ground radiation became cooling soon, which would lead to the rapid decrease of air temperature near the surface ground. Therefore, the closer to the ground it was, the lower the temperature would be. As the ground radiation cooling intensified, temperature inversion phenomenon expanded upward gradually and became strongest at the dawn. In addition, the temperature differences between different heights were the most significant at around 5:00 and the least significant at about 17:00.

Although the observed time was in different years, it can be seen that the curve pattern in January was similar to that in July, and the one in October was partially similar to that in April; however, it was not totally consistent. On January 15, 2012, the air temperature at different heights all started to rise at around 7:30 and also reached the peak at 15:00, and then the decreasing trend was showed after the peak. Moreover, the temperature above zero only existed between 13:0016:30 (Figure 2). There was also the temperature inversion phenomenon at night, which was that the air temperature increased from the ground surface to canopy.

In April, the air temperature was the most special. There were three peaks on April 14, 2012, the air temperature began to go up at around 7:00, reached the first peak at around 10:00, and rose to another peak at 15:00 and 16:30, respectively (Figure 2). Moreover, the second and the third peaks were much higher than the first one. Additionally, there was the similar temperature inversion phenomenon at night as that in October and January.

4.2. Vertical Variation of Relative Humidity inside the Forest. The relative humidity was also observed at the heights of $3 \mathrm{~m}$, $6 \mathrm{~m}$, and $10 \mathrm{~m}$ above the ground surface inside the forest on July 23 and October 6 and 2011, January 15 and April 14, 2012. It can be obtained that the variation of relative humidity inside the Robinia pseudoacacia forest was similar at different heights, but the different extent was various at different times. On July 23, 2011 and April 14, 2012, there were obvious diurnal changes, which had several different peaks and valleys, while there were not so many waves on October 6, 2011, and January 15,2012 but only one large valley. Maybe this was because of the low temperature in October and January and the small air temperature differences between night and day.
On the typical sunny days of the four seasons, the differences of relative humidity between different heights above the ground surface were larger at night while smaller in the day. In addition, the relative humidity inside the forest increased from the canopy to the ground surface during 0:00-8:00 and 20:00-23:00 (Figure 3). On July 23, 2011, the relative humidity in the day decreased from the canopy to the surface ground, and the rebound phenomenon appeared when the height fell to about $6 \mathrm{~m}$, which meant that the relative humidity at the middle height of the forest was lower, while it was higher in the forest canopy and near the ground surface. The canopy and the soil were the main parts of evapotranspiration. When the water vapor of the soil went up, the relative humidity became a little weaker, so that is why the relative humidity was higher in the part of the canopy and the ground surface, and lower at the middle height of the forest.

4.3. Vertical Variation of Wind Speed inside the Forest. Wind speed data on July 23, October 6, 2011, January 15, and April 14,2012 , was acquired at the heights of $3 \mathrm{~m}, 6 \mathrm{~m}$, and $10 \mathrm{~m}$ above the ground surface inside the forest from the meteorological station. The changing trend of wind speed was also similar at different heights. On the typical sunny days of the four seasons, the wind speed at different heights declines in the sequence of $10 \mathrm{~m}, 6 \mathrm{~m}$, and $3 \mathrm{~m}$. The wind speed at the heights of $3 \mathrm{~m}$ and $6 \mathrm{~m}$ above the ground surface was similar, and it became much stronger when reached the height of $10 \mathrm{~m}$. The stronger the wind speed was, the larger the differences between the heights of $3 \mathrm{~m}$ and $6 \mathrm{~m}$ above the ground surface would be (Figure 4).

4.4. Comparative Analysis of the Meteorological Factors inside and outside the Forest in Different Growth Periods of Robinia pseudoacacia. This study estimated the monthly average value, maximum value, and minimum value of air temperature, relative humidity, and wind speed in April (primary stage of growth period), July (peak of growth period), October (last stage of growth period), and January (nongrowth period). The results showed that the average air temperature inside the Robinia pseudoacacia forest was lower than that outside the forest in July, the same for the maximum temperature and the minimum temperature. On contrary, the average air temperature and minimum temperature inside the forest were higher than that outside the forest in January, while the maximum temperature was still lower. In April, the average air temperature and the maximum temperature inside the forest were higher, and the minimum temperature was lower (Table 2).

In conclusion, the air temperature was higher inside the forest than outside in January, April, and October when it was cool or cold, while it was lower in July when it was hot. Moreover, the maximum temperature inside the forest was lower by $2.1^{\circ} \mathrm{C}$, while the minimum temperature was higher by $0.91^{\circ} \mathrm{C}$ in January. This phenomenon indicated that the forest canopy coverage weakened the solar radiation and reduced the ground long-wave radiation as well, which lead to the slow temperature growth inside the forest and the slow temperature decrease when the outside become cool. 
TABLE 2: Statistics of meteorological factors inside and outside the forest.

\begin{tabular}{|c|c|c|c|c|c|c|c|}
\hline \multirow[b]{2}{*}{ Month } & \multirow[t]{2}{*}{ Meteorological factor } & \multicolumn{2}{|c|}{ Mean value } & \multicolumn{2}{|c|}{ Maximum value } & \multicolumn{2}{|c|}{ Minimum value } \\
\hline & & $\begin{array}{l}\text { Inside the } \\
\text { forest }\end{array}$ & $\begin{array}{l}\text { Outside the } \\
\text { forest }\end{array}$ & $\begin{array}{l}\text { Inside the } \\
\text { forest }\end{array}$ & $\begin{array}{c}\text { Outside the } \\
\text { forest }\end{array}$ & $\begin{array}{l}\text { Inside the } \\
\text { forest }\end{array}$ & $\begin{array}{c}\text { Outside the } \\
\text { forest }\end{array}$ \\
\hline \multirow{3}{*}{4} & Air temperature & 12.7 & 12.0 & 19.7 & 19.4 & 3.1 & 4.9 \\
\hline & Relative humidity & 57.5 & 48.0 & 99.0 & 59.5 & 21.9 & 38.1 \\
\hline & Wind speed & 1.7 & 2.4 & 3.5 & 3.6 & 0.7 & 1.6 \\
\hline \multirow{3}{*}{7} & Air temperature & 21.8 & 22.5 & 25.0 & 25.5 & 17.5 & 19.6 \\
\hline & Relative humidity & 67.6 & 62.3 & 96.0 & 88.6 & 42.4 & 49.0 \\
\hline & Wind speed & 1.1 & 1.7 & 1.5 & 2.5 & 0.8 & 1.1 \\
\hline \multirow{3}{*}{10} & Air temperature & 10.9 & 10.9 & 15.5 & 17.0 & 2.9 & 4.4 \\
\hline & Relative humidity & 65.2 & 64.6 & 93.6 & 90.7 & 32.3 & 51.9 \\
\hline & Wind speed & 1.3 & 1.6 & 2.1 & 2.8 & 0.7 & 0.6 \\
\hline \multirow{3}{*}{1} & Air temperature & -5.8 & -6.5 & -2.2 & -0.1 & -13.8 & -14.7 \\
\hline & Relative humidity & 68.6 & 58.0 & 96.1 & 88.7 & 38.0 & 44.9 \\
\hline & Wind speed & 1.1 & 1.5 & 2.1 & 2.4 & 0.4 & 0.0 \\
\hline
\end{tabular}

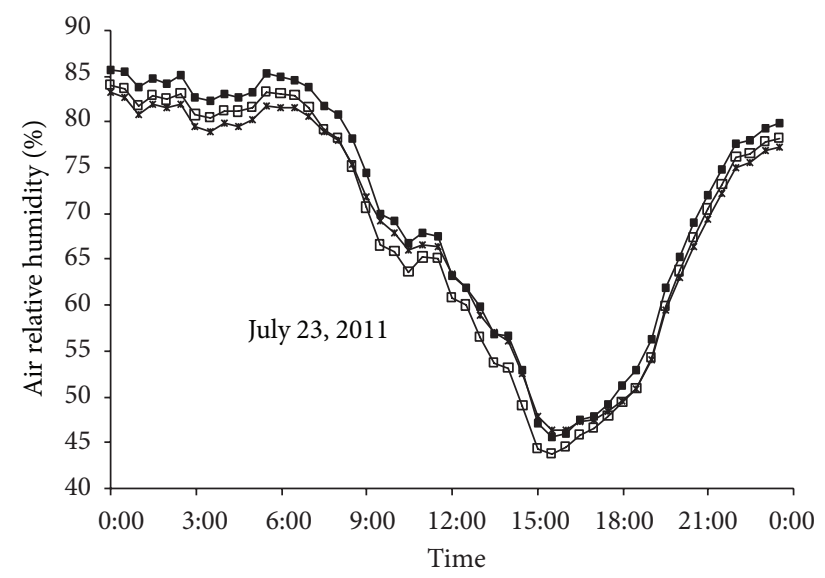

(a)

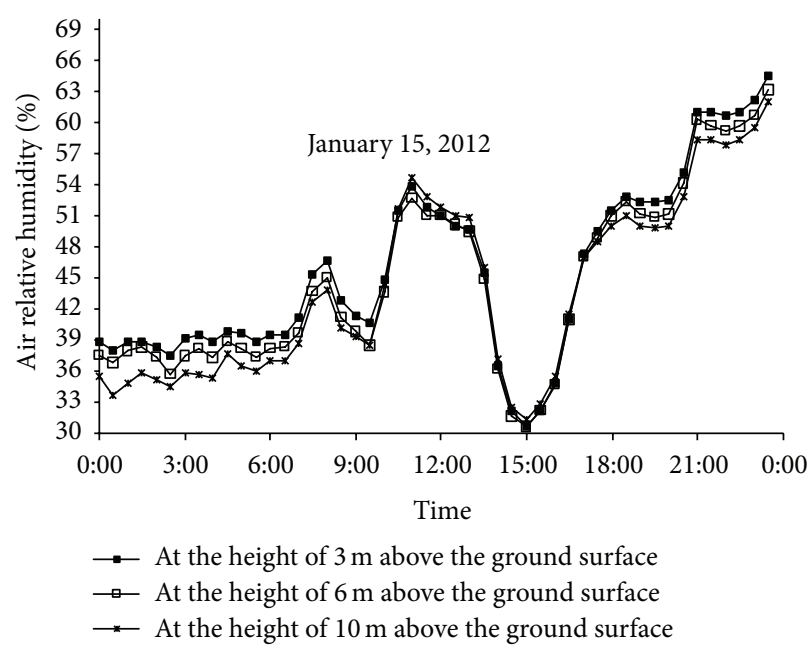

(c)

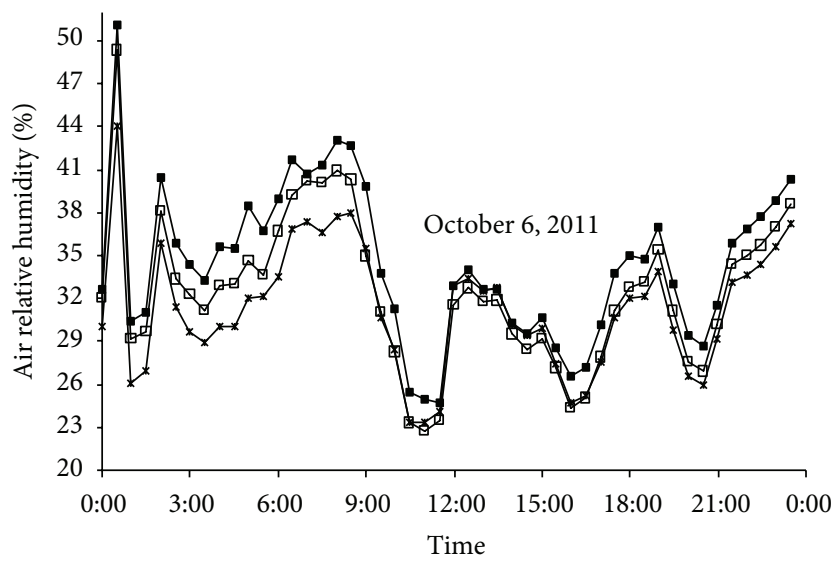

(b)

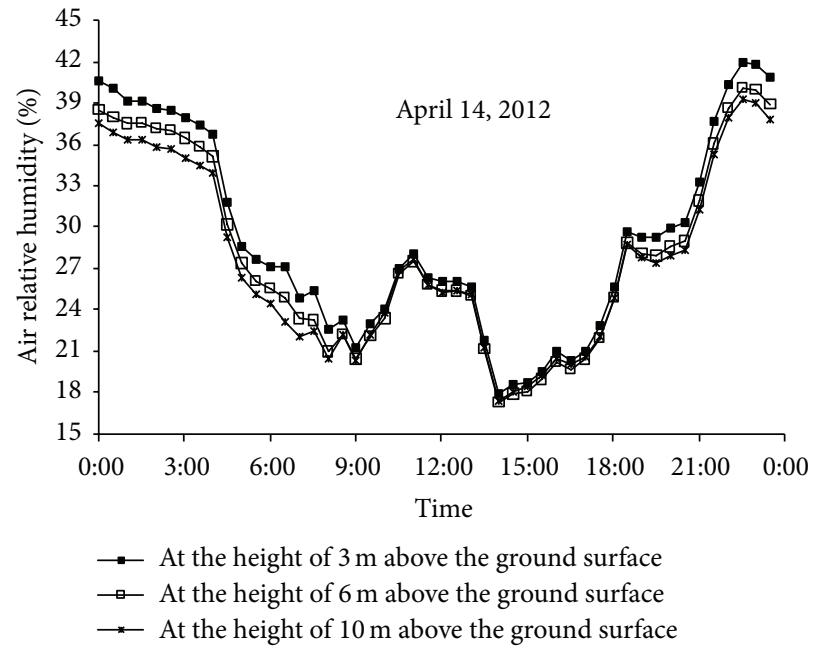

(d)

FIGURE 3: Dynamic variation of relative humidity at the heights of $3 \mathrm{~m}, 6 \mathrm{~m}$, and $10 \mathrm{~m}$ above the ground surface inside the forest. 


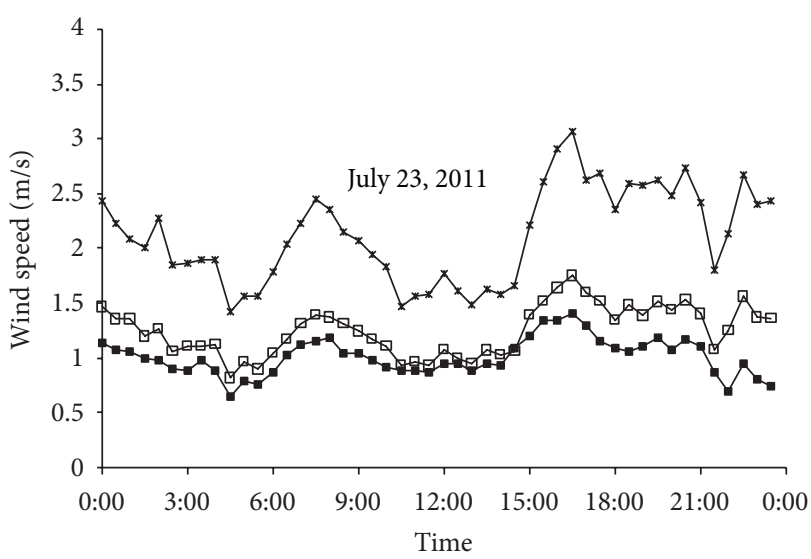

(a)

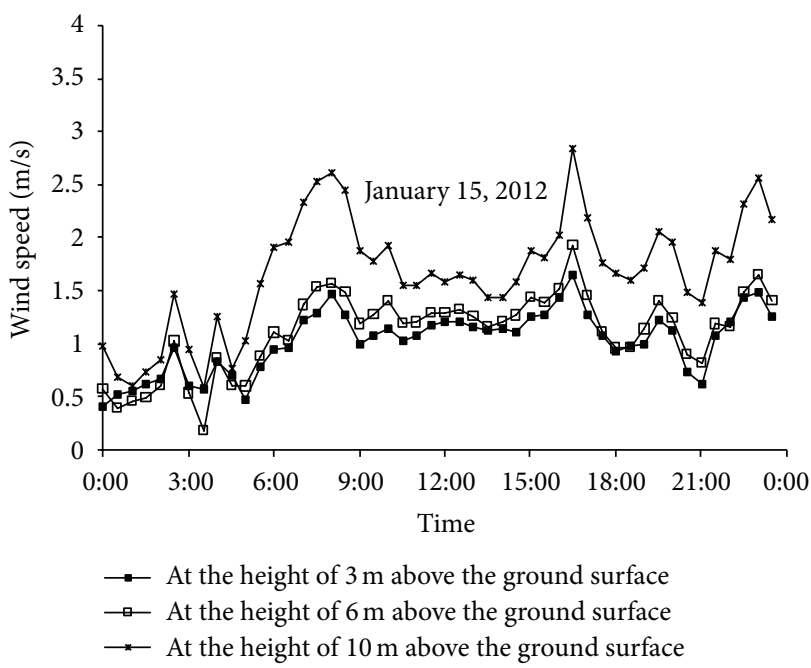

(c)

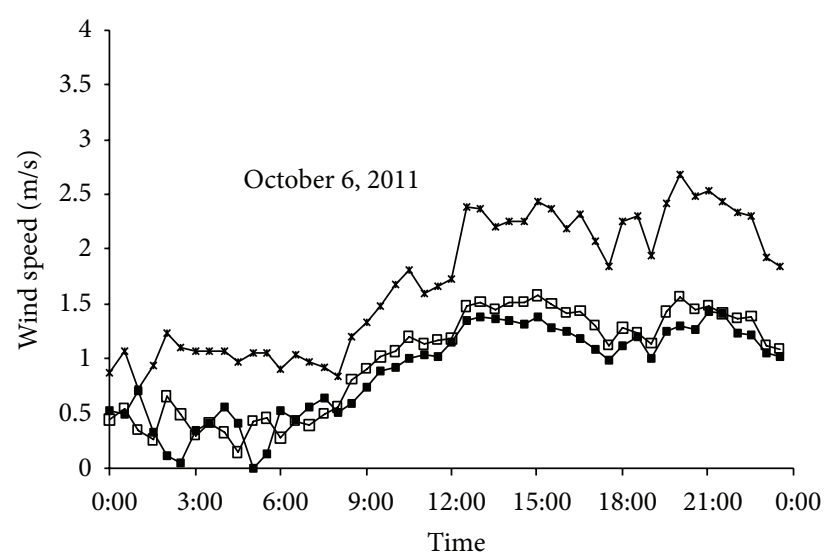

(b)

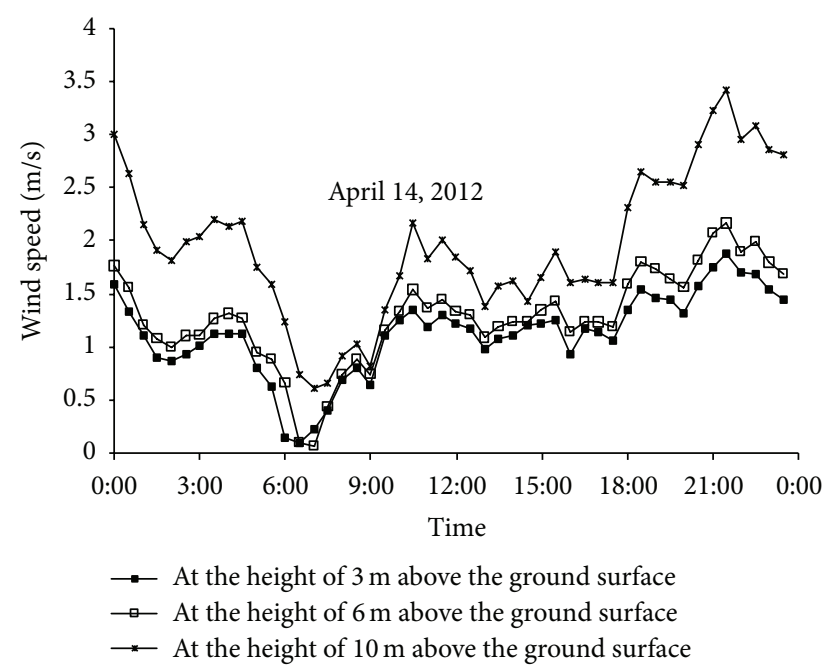

(d)

FIGURE 4: Dynamic variation of wind speed at the heights of $3 \mathrm{~m}, 6 \mathrm{~m}$, and $10 \mathrm{~m}$ above the ground surface inside the forest.

Therefore, it made the maximum temperature reduce and the minimum temperature increase inside the forest.

The mean value and the maximum value of relative humidity inside the forest were larger than outside, while it was contrary for the wind speed. Thus, it can be seen that the Robinia pseudoacacia forest increased the relative humidity and slowed down the wind speed. This phenomenon may be caused by the fact that the cover effect of the forest canopy weakened the wind speed and turbulent exchange inside the Robinia pseudoacacia forest and made the water vapor from plant transpiration and soil evaporation hang in the surface atmosphere for a long time, so that the relative humidity was higher inside the forest than outside.

\section{Diurnal Fluctuation of the PET at Different Heights above the Ground Surface inside the Forest in Different Growth Periods of Robinia pseudoacacia}

5.1. Vertical Variation of PET inside the Forest in April. April, the arid and windy season of Loess Plateau with gradual temperature rising, is the primary stage of growth of Robinia pseudoacacia, leaves begin to unfold and photosynthesis and transpiration rate gradually grow, so water consumption of potential evapotranspiration continually increases as well. This study analyzed the potential evapotranspiration changes at different heights above the ground surface inside the Robinia pseudoacacia forest under different weather conditions during the period from April 24 to April 27, which was rainy on April 24 and sunny from April 25 to April 27.

The estimation results illustrated that the changing trends of potential evapotranspiration were similar under different weather conditions at different heights above the ground surface (Figure 5). In the sunny days, there was a bimodal curve in the potential evapotranspiration changes, which began to rise rapidly from about 6:00-7:00, up to the first peak at around 8:00-10:00, and it stayed at the peak for some time. A break phenomenon appeared at noon at about 12:00-13:00, reached the peak once again at about 15:00, and then dropped down at the bottom of the valley at about 19:00. However, there was still some potential evapotranspiration at different heights even at night. In addition, the potential evapotranspiration in the sunny days was significantly greater than that in 


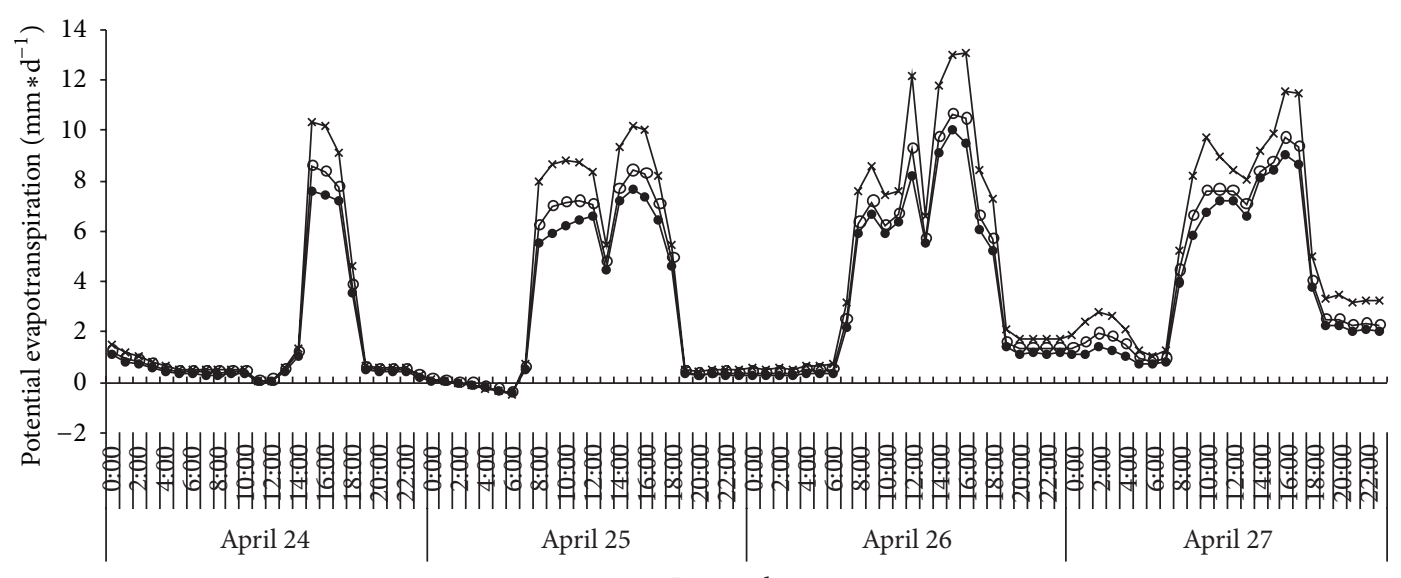

Date and time

$\rightarrow$ At the height of $3 \mathrm{~m}$ above the ground surface
$\rightarrow$ At the height of $6 \mathrm{~m}$ above the ground surface
$\rightarrow$ At the height of $10 \mathrm{~m}$ above the ground surface

FIGURE 5: Diurnal fluctuation of the PET at the heights of $3 \mathrm{~m}, 6 \mathrm{~m}$, and $10 \mathrm{~m}$ above the ground surface inside the forest in April.

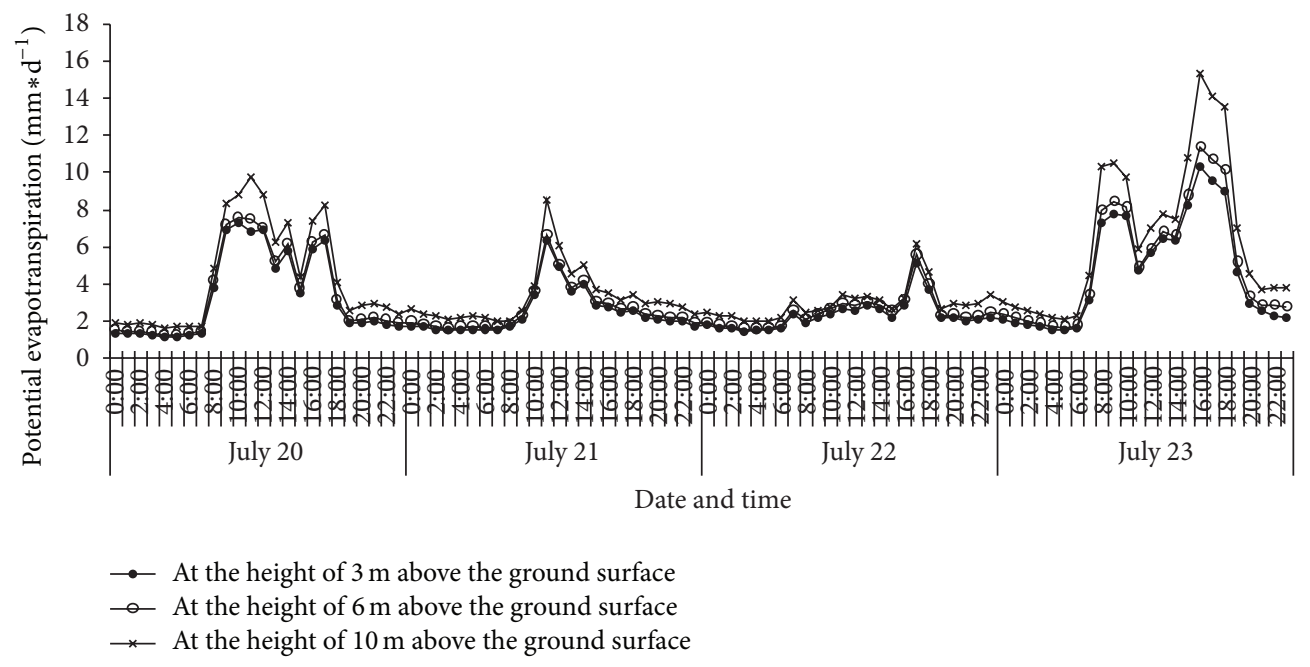

FIgURE 6: Diurnal fluctuation of the PET at the heights of $3 \mathrm{~m}, 6 \mathrm{~m}$, and $10 \mathrm{~m}$ above the ground surface inside the forest in July.

the rainy days. In the rainy days, the solar radiation intensity was relatively smaller and the sunshine hours were less, so the average daily potential evapotranspiration was obviously less than that in the sunny days, which showed only a single and narrow peak, starting to rise at 13:00, reached its peak at 15:00, and then dropped to the bottom at 19:00. On comparing the potential evapotranspiration at night with that in the day, there was no significant variation at the different heights above the ground surface at night, contrarily, it was obvious in the day, and the potential evapotranspiration inside the forest decreased in the sequence of $10 \mathrm{~m}, 6 \mathrm{~m}$, and $3 \mathrm{~m}$.

5.2. Vertical Variation of PET inside the Forest in July. In July, the rainfall was abundant and the solar radiation intensity was strong. It was also the peak season of potential evapotranspiration in a year. This study explored the potential evapotranspiration changes at different heights above the ground surface under different weather conditions inside the Robinia pseudoacacia forest during the period from July 20 to July 23 , which was shower on July 20 , overcast and rainy on July 21 and July 22, and sunny on July 23.

It was almost the same as in April that the changing trend of potential evapotranspiration was also similar at different heights under different weather conditions (Figure 6). The potential evapotranspiration changing curve inside the forest showed the bimodal pattern not only in the sunny days, but also in the shower days, and it was also to grow at 6:00-7:00, and then it showed the downward trend after it got to the first peak at 11:00. It began to decline once again after the second peak at 17:00 and reached the valley at about 19:00. Potential evapotranspiration at night still occurred at different heights, and the potential evapotranspiration in the sunny days was extremely larger than that in the shower days as well. In the overcast and rainy days with weaker solar radiation intensity 


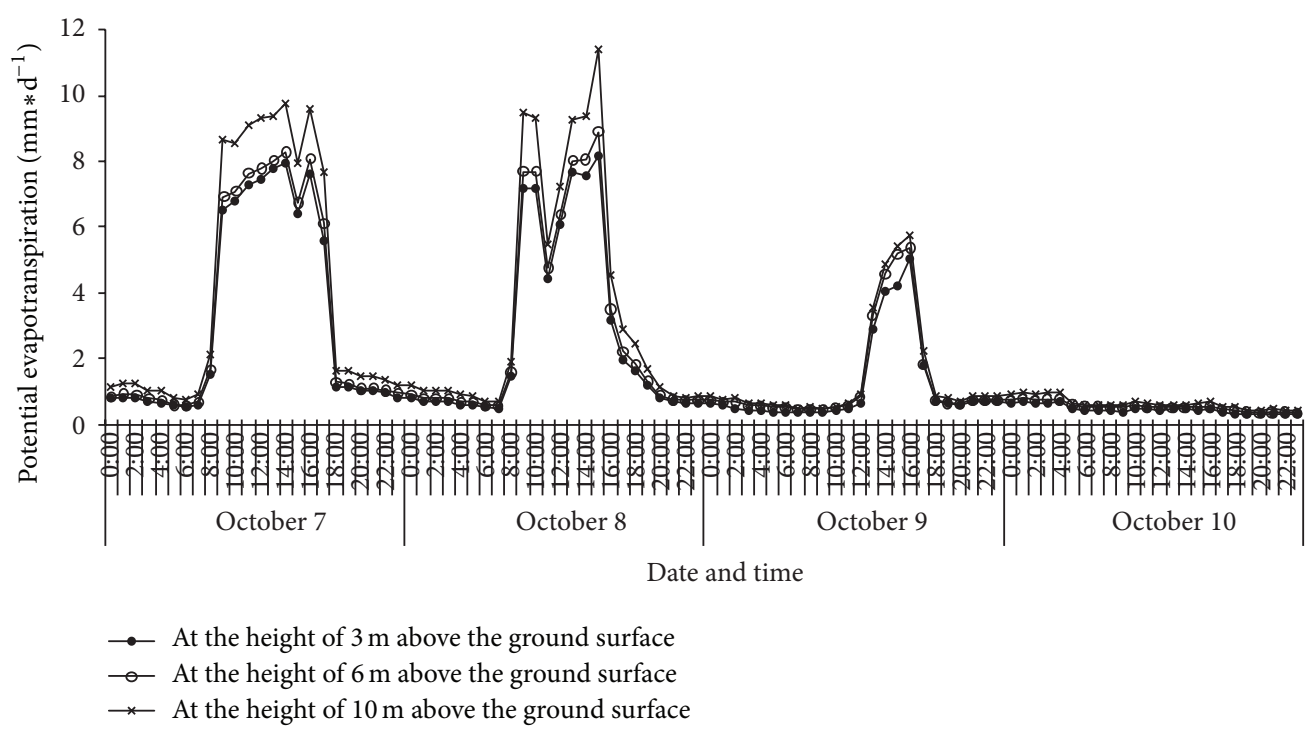

FIgURE 7: Diurnal fluctuation of the PET at the heights of $3 \mathrm{~m}, 6 \mathrm{~m}$, and $10 \mathrm{~m}$ above the ground surface inside the forest in October.

and less sunshine hours, the potential evapotranspiration was obviously smaller than that in the sunny days and shower days. It had the single peak type curve, the fluctuation was small, and the peak time was not stable. It was at the peak at around 12:00 on July 21 , while at 17:00 on July 22 . This may be aroused by the various solar radiations in different overcast and rainy days. Although the air temperature was higher in July, however, the differences of potential evapotranspiration at different heights differed slightly at night and greatly in the day, and the potential evapotranspiration inside the forest had the same sequence as in April, which is $10 \mathrm{~m}>6 \mathrm{~m}>3 \mathrm{~m}$.

5.3. Vertical Variation of PET inside the Forest in October. October was the last stage of the growth period with less rainfall and low air temperature, and the potential evapotranspiration inside the forest was gradually weakened. This study selected 4 typical days from October 6 to October 10, and explored the potential evapotranspiration changes inside the Robinia pseudoacacia forest at different heights. During the research period, it was sunny on October 7 and October 8, rainy on October 9 and October 10.

The results were represented in Figure 7, and it can be seen that the heights above the ground surface did not overturn the changing trend of the potential evapotranspiration regardless to the weather condition in October. In the sunny days, a bimodal curve was also shown in the potential evapotranspiration changes, which rose from 6:00 to 7:00, declined after it reached the first peak at 12:00, decreased once again following the second peak at 15:00, and finally got to the valley at around 19:00; however, it would not drop to zero even at night. The average potential evapotranspiration in the sunny days was higher than that in the rainy days. In the rainy days, the potential evapotranspiration changes depended on the solar radiation to some extent. There was certain solar radiation on October 9, and the potential evapotranspiration changes inside the Robinia pseudoacacia forest showed the single peak curve, and the time that it took to get to the peak is consistent with the time of the second peak in the sunny days. On October 10, the solar radiation intensity was close to zero, and the sunshine hours were zero, so the potential evapotranspiration had no fluctuation basically, and it was very weak, close to zero.

5.4. Vertical Variation of PET inside the Forest in January. Air temperature of Loess Plateau was low in January, and leaves of Robinia pseudoacacia had been completely off, so there were faint photosynthesis and transpiration, and the potential evapotranspiration was quite small. This study selected four typical days from the 18th to the 21st of January, 2012, to conduct the researches on the potential evapotranspiration changes inside the Robinia pseudoacacia forest at different heights above the ground surface.

It was different from other seasons, the potential evapotranspiration inside the Robinia pseudoacacia forest had a single peak curve in the sunny days, and the time of rising up to the peak was also different from the other three months, which started rising at about 10:00, but the growth rate began to reduce at around 11:00, reached the peak when it was about 15:00, and then down to the valley until 17:00 (Figure 8). In the snowy days, the solar radiation intensity was weak, and the sunshine hours were less. So, there was no obvious fluctuation except the small extent waves during 11:00-16:00 on January 19. The potential evapotranspiration inside the Robinia pseudoacacia forest was negative in the snowy days, and it was similar even in the sunny days. It indicated that the air temperature at night was extremely low whether in the sunny days or the snowy days in the study area, and the condensation was larger than potential evapotranspiration. The differences of potential evapotranspiration between the different heights above the ground surface were smaller at the night of sunny days and snowy days of January, but it was large at the day time of the sunny days. The sequence of potential evapotranspiration inside the forest was that $10 \mathrm{~m}>$ $6 \mathrm{~m}>3 \mathrm{~m}$. 


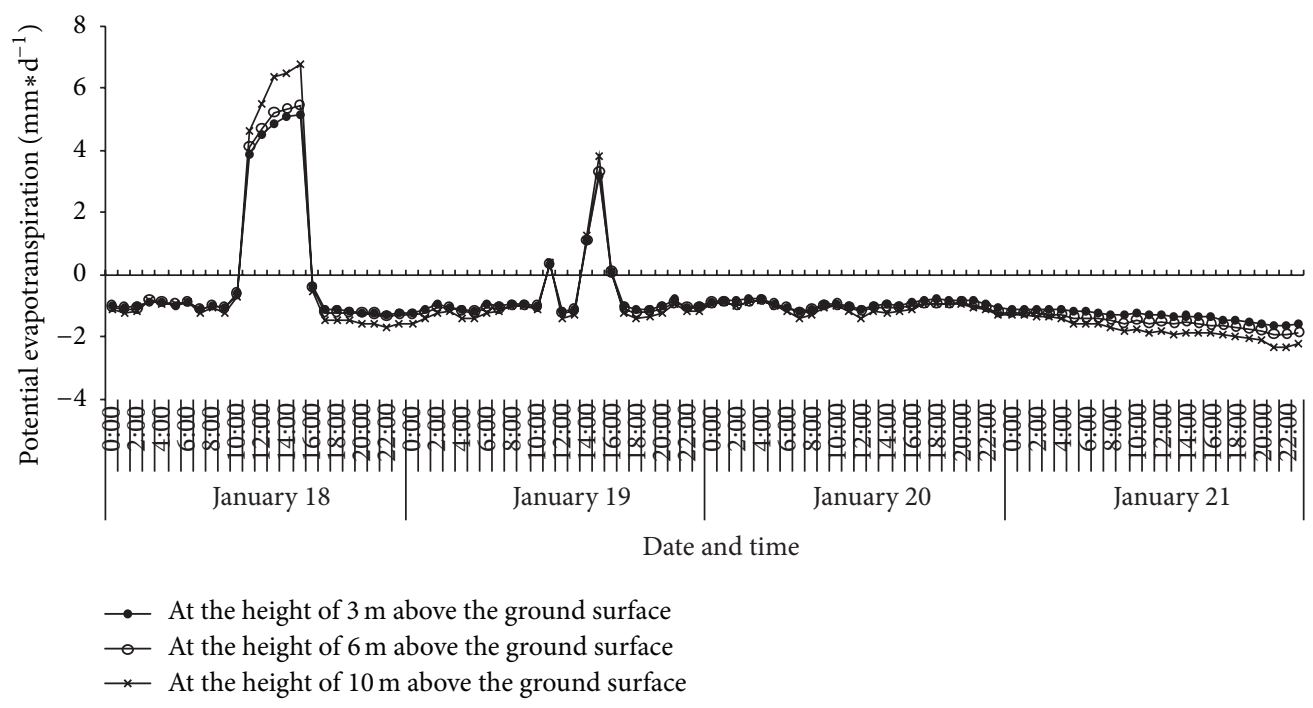

Figure 8: Diurnal fluctuation of the PET at the heights of $3 \mathrm{~m}, 6 \mathrm{~m}$, and $10 \mathrm{~m}$ above the ground surface inside the forest in January.

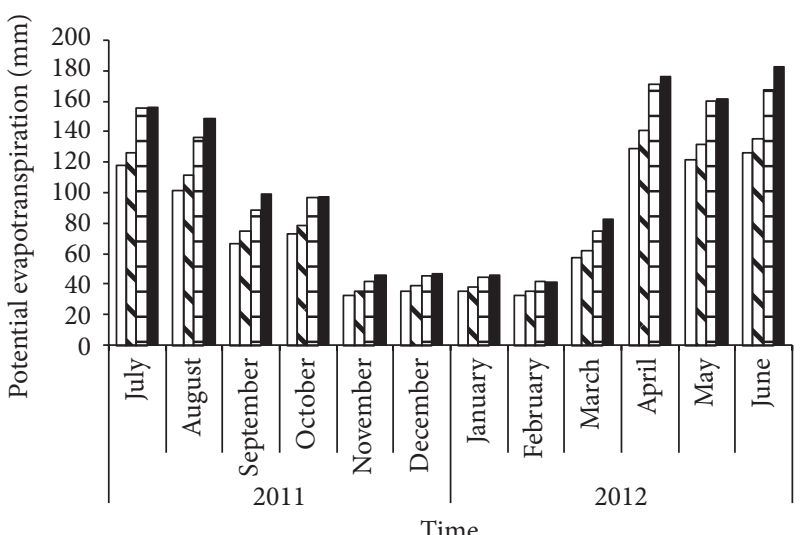

$\square$ At the height of $3 \mathrm{~m}$ above the ground surface inside the forest $\square$ At the height of $6 \mathrm{~m}$ above the ground surface inside the forest $\square$ At the height of $10 \mathrm{~m}$ above the ground surface inside the forest Outside the forest

FIgure 9: Comparison of the mean monthly PET at the heights of $3 \mathrm{~m}, 6 \mathrm{~m}$, and $10 \mathrm{~m}$ inside and outside the forest.

5.5. Comparative Analysis of Monthly Average PET at Different Heights inside and outside the Forest from July 2011 to June 2012. This study estimated the monthly potential evapotranspiration inside and outside the forest, respectively. The results represented that the monthly average potential evapotranspiration inside the Robinia pseudoacacia forest was similar at different heights from July 2011 to June 2012 (Figure 9). Comparing the potential evapotranspiration of each month, it can be obtained that the monthly potential evapotranspiration changed in different months as follows: April > June > May $>$ July $>$ August $>$ October $>$ September $>$ March $>$ December $>$ January $>$ November $>$ February. It was the highest in April with the $129.1 \mathrm{~mm}, 140.3 \mathrm{~mm}$, and $171.1 \mathrm{~mm}$ potential evapotranspiration at the heights of $3 \mathrm{~m}, 6 \mathrm{~m}$, and
$10 \mathrm{~m}$, respectively, and it was the lowest in January, and the monthly potential evapotranspiration was only $32.54 \mathrm{~mm}$, $35.06 \mathrm{~mm}$, and $41.51 \mathrm{~mm}$ at the heights of $3 \mathrm{~m}, 6 \mathrm{~m}$, and $10 \mathrm{~m}$, respectively. The reason why it is higher in April and May may be because it is drier in this period, and moreover, there are strong winds which promote the growth of the potential evapotranspiration. The air temperature is higher in June and July, so potential evapotranspiration is relatively high in these two months. In the open space outside the forest, the monthly potential evapotranspiration was different, whose sequence was June $>$ April $>$ May $>$ July $>$ August $>$ September $>$ October $>$ March $>$ December $>$ November $>$ January $>$ February. The potential evapotranspiration at different heights inside the forest was compared with that in the open space, and the results indicate that the sequence was open space $>10 \mathrm{~m}>$ $6 \mathrm{~m}>3 \mathrm{~m}$.

During the period from April to August, the monthly potential evapotranspiration at the heights of $3 \mathrm{~m}, 6 \mathrm{~m}$, and $10 \mathrm{~m}$ above the ground surface inside the forest was $119.2 \mathrm{~mm}$, $128.9 \mathrm{~mm}$, and $157.8 \mathrm{~mm}$, respectively, and it was $164.9 \mathrm{~mm}$ in the open space outside the forest, all of which were much larger than that of other months, being 2.49, 2.48, 2.56, and 2.52 times of that in other months, respectively. The difference between the open space and $10 \mathrm{~m}$ height above the ground surface was the smallest, with only $5.1 \mathrm{~mm}$, and it was the largest between the open space and $3 \mathrm{~m}$ height above the ground surface, which was $22.9 \mathrm{~mm}$. The one between $10 \mathrm{~m}$ height and $3 \mathrm{~m}$ height above the ground surface was $17.8 \mathrm{~mm}$ and between $6 \mathrm{~m}$ height and $3 \mathrm{~m}$ height above the ground surface was $6.4 \mathrm{~mm}$.

\section{Conclusions}

This study acquires the following conclusions.

(1) In the typical sunny days of the four seasons, there had been similar changing trends at the different heights inside the Robinia pseudoacacia forest for the air 
temperature, relative humidity, and wind speed, and the changing extent was however various in different times. Among them, air temperature in the Robinia pseudoacacia forest all showed a significant diurnal variation in the typical sunny days of the four seasons. But for the relative humidity, the significant diurnal variation only existed in April and July, but not in January and October. Through the analysis of vertical variation of air temperature and relative humidity inside the Robinia pseudoacacia forest, it can be found that there was a temperature inversion phenomenon during some periods of time. The relative humidity in the day time was relatively lower at the middle height of the forest and higher in the canopy part and the near-surface ground part, while it would increase from the canopy to the surface ground at night. As for the wind speed, it was higher at the higher parts of the forest.

(2) According to the study, in January, April, and October, the air temperature inside the forest was higher than that of the open space outside the forest, while it was lower in July. In January, the maximum temperature in the forest was $2.1^{\circ} \mathrm{C}$ lower than that of the outside, and the minimum temperature was contrarily higher by $0.91^{\circ} \mathrm{C}$ than that of the outside. The mean and maximum value of relative humidity of each month inside the Robinia pseudoacacia forest were all higher than that of the outside, while it was totally different for wind speed, the mean and maximum values were lower inside the forest.

(3) This study found that the changing trends of potential evapotranspiration were almost similar at different heights, but it was various under different weather conditions. Among them, the potential evapotranspiration had the obvious diurnal changing trend, which showed the bimodal curve in the typical sunny days and rainy days of April, July, and October, while the diurnal rules were not significant any more in the rainy days, and the changing curve became singlepeak pattern with smaller fluctuation. As for the potential evapotranspiration, differences between different heights were not obvious at night and were great in the day, which was represented by $10 \mathrm{~m}>$ $6 \mathrm{~m}>3 \mathrm{~m}$. While the potential evapotranspiration inside the forest showed the single-peak curve in January, and there were no fluctuations in the snowy days. The differences of potential evapotranspiration between different heights were less significant at night and in the snowy days and more significant in the sunny days. The further from the ground it was, the less the potential evapotranspiration was.

(4) This study indicated that the monthly potential evapotranspiration at the heights of $3 \mathrm{~m}, 6 \mathrm{~m}$, and $10 \mathrm{~m}$ above the ground surface inside the Robinia pseudoacacia forest was consistent from July 2011 to June 2012, and the monthly potential evapotranspiration changed with the month as follows: April > June >
May $>$ July $>$ August $>$ October $>$ September $>$ March $>$ December $>$ January $>$ November $>$ February, while the potential evapotranspiration in the open space outside the forest follows the sequence as June $>$ April $>$ May $>$ July $>$ August $>$ September $>$ October $>$ March $>$ December $>$ November $>$ January $>$ February. In addition, the monthly mean value of the potential evapotranspiration in the open space outside the forest was larger than that inside the forest at the height of $10 \mathrm{~m}$, followed was that at the height of $6 \mathrm{~m}$, and the smallest was that at the height of $3 \mathrm{~m}$.

(5) The potential evapotranspiration from April to August was significantly higher than that in other months whether it was inside the forest or in the open space outside the forest. The difference between the open space outside the forest and $10 \mathrm{~m}$ height above the ground surface was least significant, and it differed most greatly between the open space and $3 \mathrm{~m}$ height above the ground surface. The mean monthly potential evapotranspiration value, at the heights of $3 \mathrm{~m}, 6 \mathrm{~m}$, and $10 \mathrm{~m}$ above the ground surface from July 2011 to June 2012, was $930.9 \mathrm{~mm}, 1007.6 \mathrm{~mm}$, and $1221.5 \mathrm{~mm}$, respectively, and it was $1282.9 \mathrm{~mm}$ in the open space outside the forest.

\section{Acknowledgments}

This research was supported by the key projects in the National Science \& Technology Pillar Program during the Twelfth Five-year Plan Period (no. 2011BAD38B06), National Basic Research Program of China (973 Program) (nos. 2010CB950904; 2012CB95570001), and New teaches' scientific research program funded by Beijing Forestry University (no. BLX2012044). Data supports from the national field observation station of Ji County.

\section{References}

[1] X. N. Zhao, P. H. Wu, H. Feng, Y. Wang, and H. Shao, "Constructing ecological-protecting barrier: basic research of rainfall runoff regulation and application in the loess plateau of China and its implications for global arid areas," African Journal of Biotechnology, vol. 8, no. 19, pp. 4717-4723, 2009.

[2] C. Liu, M. Shao, Y. Wang et al., "Status quo of water science \& technology development in China and abroad," in Water Science \& Technology in China: A Roadmap to 2050, pp. 37-52, Springer, Berlin, Germany, 2012.

[3] S. Gebhart, K. Radoglou, G. Chalivopoulos et al., "Evaluation of potential evapotranspiration in central macedonia by EmPEst," in Advances in Meteorology, Climatology and Atmospheric Physics, pp. 451-456, Springer, Berlin, Germany, 2013.

[4] H. Paeth, K. Born, R. Girmes, R. Podzun, and D. Jacob, "Regional climate change in tropical and northern africa due to greenhouse forcing and land use changes," Journal of Climate, vol. 22, no. 1, pp. 114-132, 2009.

[5] Y. Yin, S. Wu, D. Zhao et al., "Modeled effects of climate change on actual evapotranspiration in different eco-geographical regions in the tibetan plateau," Journal of Geographical Sciences, vol. 23, no. 2, pp. 195-207, 2013. 
[6] G. G. Katul, R. Oren, S. Manzoni et al., "Evapotranspiration: a process driving mass transport and energy exchange in the soilplant-atmosphere-climate system," Reviews of Geophysics, vol. 50, no. 3, 2012.

[7] G. Papadavid, D. G. Hadjimitsis, S. Michaelides et al., "A comparison of a hydrological and an energy balance model for estimating evapotranspiration of chickpeas at paphos (SW Cyprus) agricultural area," in Advances in Meteorology, Climatology and Atmospheric Physics, pp. 247-252, Springer, Berlin, Germany, 2013.

[8] J. M. Clarke, "Effect of drought stress on residual transpiration and its relationship with water use of wheat," Canadian Journal of Plant Science, vol. 1, no. 3, pp. 695-702, 2000.

[9] A. Schneider, S. Arnold, D. Doley et al., "The importance of plant water use on evapotranspiration covers in semi-arid Australia," Hydrology and Earth System Sciences, vol. 9, pp. 1191111940, 2012.

[10] R. Leuning, Y. Q. Zhang, A. Rajaud, H. Cleugh, and K. Tu, "Correction to 'A simple surface conductance model to estimate regional evaporation using MODIS leaf area index and the penman-monteith equation"' Water Resources Research, vol. 45, no. 1, 2009.

[11] M. Pirkner, U. Dicken, and J. Tanny, "Penman-Monteith approaches for estimating crop evapotranspiration in screenhouses-a case study with table-grape," International Journal of Biometeorology, 2013.

[12] S. Irmak, L. O. Odhiambo, and D. Mutiibwa, "Evaluating the impact of daily net radiation models on grass and alfalfa-reference evapotranspiration using the penman-monteith equation in a subhumid and semiarid climate," Journal of Irrigation and Drainage Engineering, vol. 137, no. 2, pp. 59-72, 2011.

[13] B. N. Guo, J. J. Zhang, Z. Wang et al., "Characteristics of water consumption by Robinia pseudoacacia forest on loess plateau of western shanxi province, China," Chinese Journal of Ecology, vol. 31, no. 11, pp. 2736-2741, 2012 (Chinese).

[14] Q. Guo, B. Zhang, J. Zhong, J. Tan, B. Luo, and X. Huang, "Variation characteristics and calculation model of evapotranspiration in latored soils on hills," Chinese Journal of Applied Ecology, vol. 14, no. 4, pp. 512-514, 2003 (Chinese).

[15] J. F. Li, Optimal Allocation of Agricultural Water Resources Based on Virtual Water Strategy in Shiyang River Basin, North West Agriculture and Forestry University, 2012.

[16] P. Annighöfer, I. Mölder, S. Zerbe, H. Kawaletz, A. Terwei, and C. Ammer, "Biomass functions for the two alien tree species Prunus serotina Ehrh. and Robinia pseudoacacia L in floodplain forests of Northern Italy," European Journal of Forest Research, vol. 131, no. 5, pp. 1619-1635, 2012.

[17] W. Gong, Y. G. Gong, T. X. Hu et al., "Study of microclimate characteristics of Pinus elliottii plantations in northern Sichusan Basin," Journal of Sichuan Forestry Science and Technology, vol. 27, no. 3, pp. 5-14, 2006 (Chinese).

[18] X. X. Zhou, J. J. Zhang, X. H. Sui et al., “Transpiration characteristics of Robinia pseudoacacia L. with different densities during the peak season," Bulletin of Soil and Water Conservation, vol. 30, no. 3, pp. 42-47, 2010 (Chinese).

[19] C. F. Liu, Z. Q. Zhang, J. T. Guo et al., "Transpiration of a pinus tabulaeformis and Robinia pseudoacacia mixed forest in hilly gully region of the loess plateau, west shanxi province," Science of Soil and Water Conservation, vol. 8, no. 5, pp. 42-48, 2010 (Chinese).

[20] K. Staudt, A. Serafimovich, L. Siebicke, R. D. Pyles, and E. Falge, "Vertical structure of evapotranspiration at a forest site (A Case
Study)," Agricultural and Forest Meteorology, vol. 151, no. 6, pp. 709-729, 2011.

[21] S. Z. Kang, "Calculating method of potential atmospheric evaporation in the arid and semiarid areas," Agriculture Research in the Arid Areas, vol. 1, no. 2, pp. 41-50, 1985 (Chinese). 

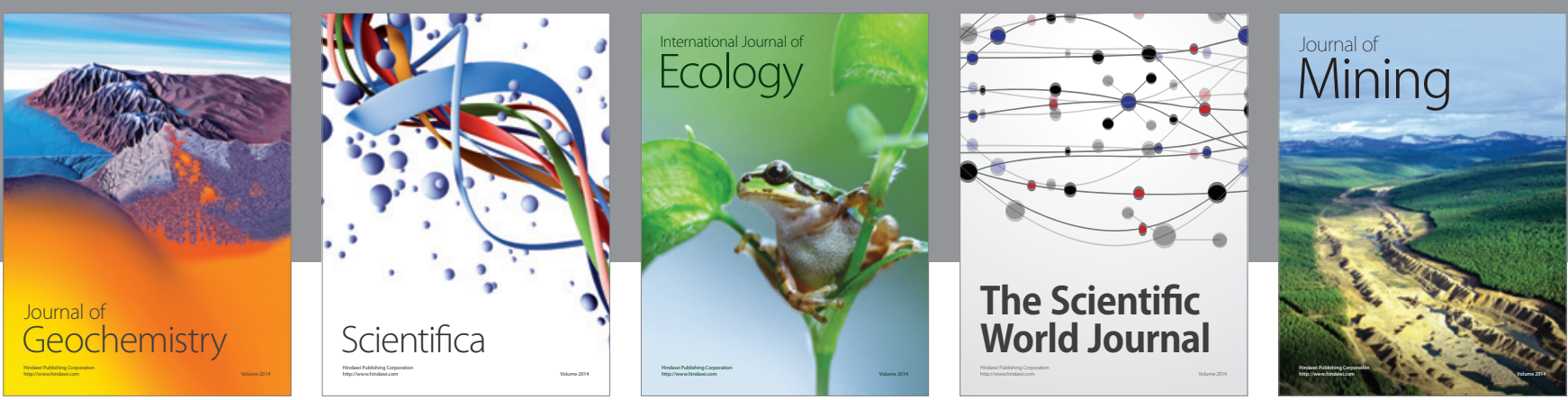

The Scientific World Journal
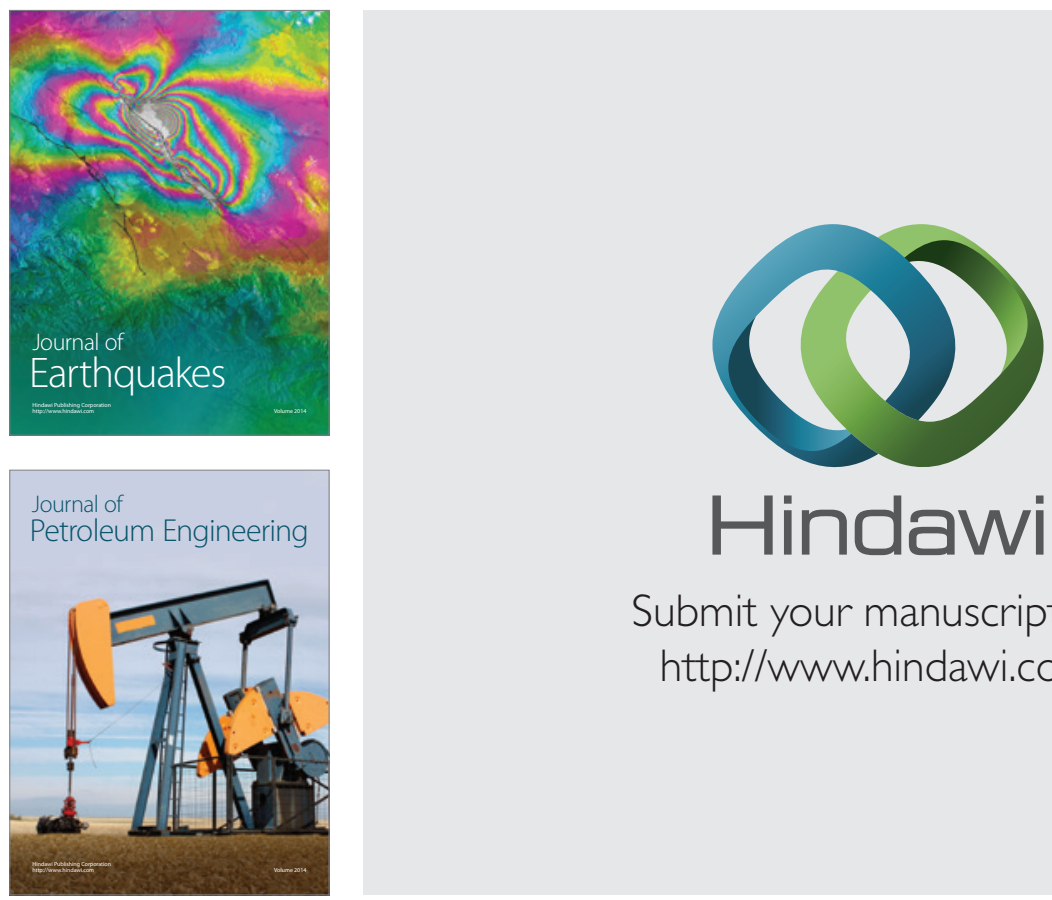

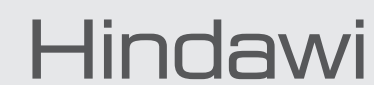

Submit your manuscripts at

http://www.hindawi.com
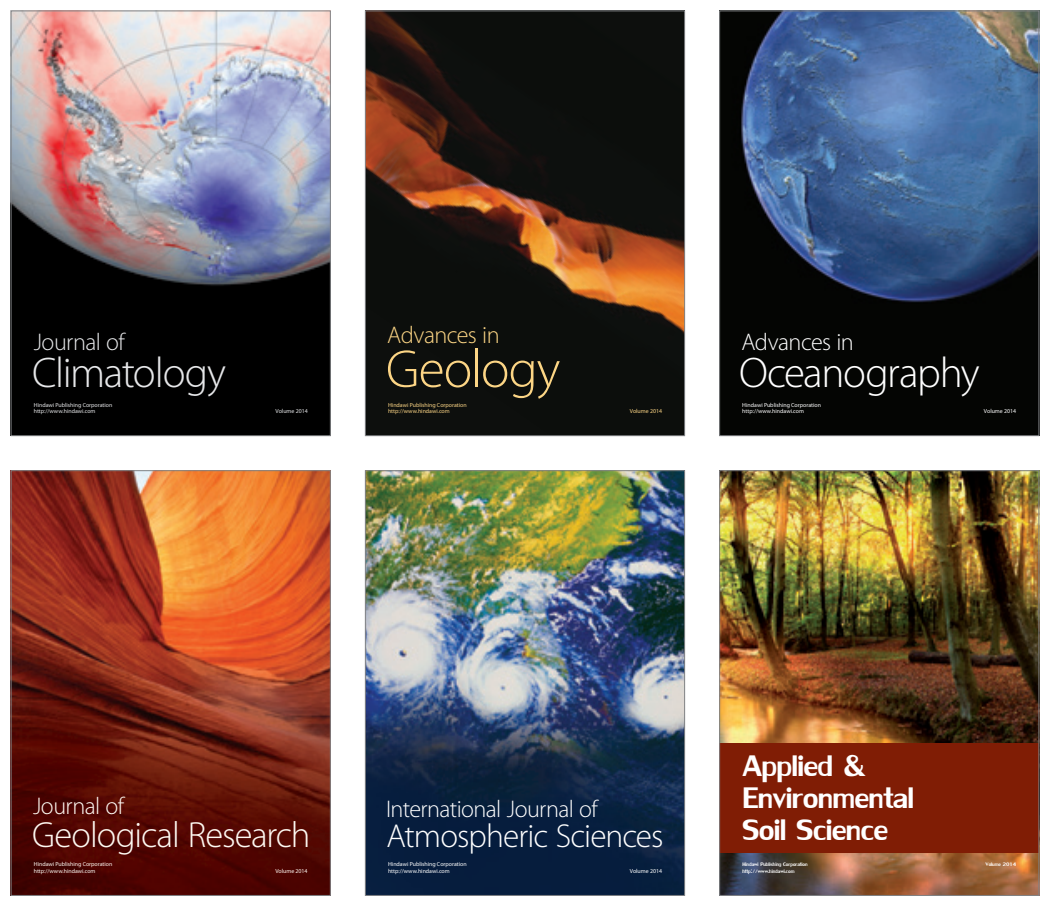
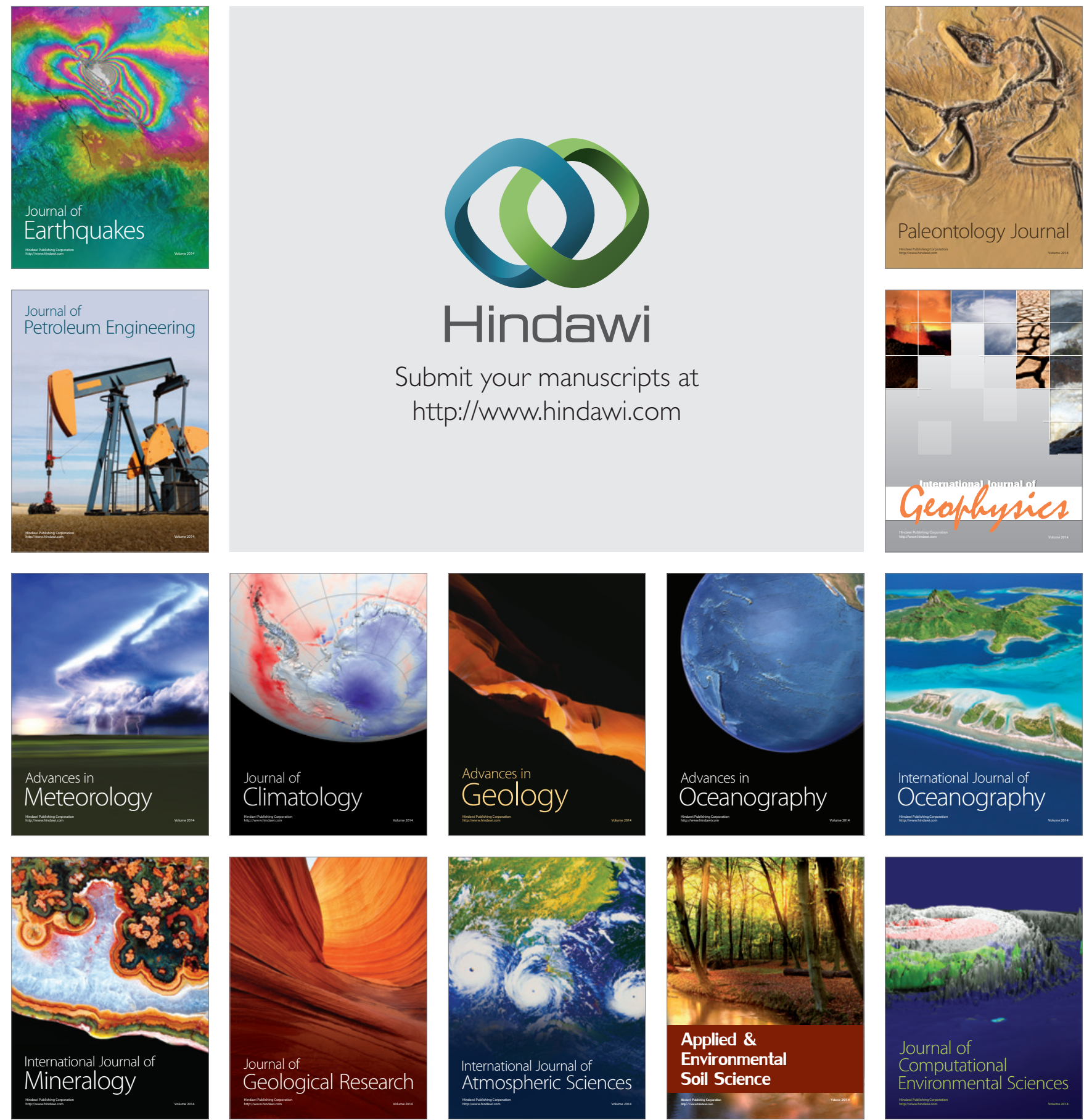